\title{
Design and Optimization of Genetic Algorithm (GA) based High Gain and Directive CPW-Fed Slot Dipole Antenna for Wideband Applications
}

\author{
Raj Gaurav Mishra, Ranjan Mishra, N. Prasanthi Kumari, Sushabhan Choudhury, \\ Piyush Kuchhal
}

\begin{abstract}
Genetic Algorithm (GA) is proposed in this paper for the design of a wide bandwidth, high gain and directive $C P W$-fed slot-dipole antenna. The proposed antenna is built on a FR4 substrate that is cheap and easy to produce. Genetic Algorithm is used to select parameters that reflect antenna geometry to achieve wider bandwidth and reduced return loss (parameter S11) and high gain values at resonant frequency. The antenna design shows a wide operating bandwidth of $1.4 \mathrm{GHz}$ (simulated) and 1.3 $\mathrm{GHz}$ (measured) over the $\mathrm{X}$-band, a return loss (S11) of $-25.83 \mathrm{~dB}$ (simulated) and -23.08 (measured) and a gain and directivity of $5.61 \mathrm{~dB}$ (simulated) and $11.87 \mathrm{~dB}$ (simulated) at $10.5 \mathrm{GHz}$ resonating frequencies. In this work, all simulations were performed using the ANSYS HFSS v14.0 software. A prototype antenna was produced and then characterized using VNA to validate the design. Measurement results were in good agreement with the results simulated using ANSYS HFSS.
\end{abstract}

Keywords :Antenna Optimization, CPW-fed Slot Dipole Antenna, Genetic Algorithm, High Gain, High Directivity Antenna.

\section{INTRODUCTION}

Many successful wireless communication applications are expected from microstrip antennas due to its attractive low profile, lightweight, fast manufacturing and strong circuit integration capabilities [1]. Because of their excellent electrical and mechanical properties, compatibility with other RF systems [2], printed patch antennas are suitable for wide-band applications. However, the standard microstrip

Revised Manuscript Received on December 30, 2019.

* Correspondence Author

Raj Gaurav Mishra, Department of Electrical \& Electronics Engineering, School of Engineering, University of Petroleum \& Energy Studies, Dehradun , India. rgmishra@ddn.upes.ac.in

Ranjan Mishra, Associate Professor, Department of Electrical \& Electronics Engineering, School of Engineering, University of Petroleum \& Energy Studies, Dehradun , India. rmishra@ddn.upes.ac.in

N. Prasanthi Kumari, Associate Professor, Department of Electrical \& Electronics Engineering, School of Engineering, University of Petroleum \& Energy Studies, Dehradun, India. prasanti@ddn.upes.ac.in

Sushabhan Choudhury, Professor and Head, Department of Electrical \& Electronics Engineering, School of Engineering, University of Petroleum \& Energy Studies, Dehradun , India. schoudhury@ddn.upes.ac.in

Piyush Kuchhal, Professor, Department of Physics, School of Engineering, University of Petroleum \& Energy Studies, Dehradun , India pkuchhal@ddn.upes.ac.in

(C) The Authors. Published by Blue Eyes Intelligence Engineering and Sciences Publication (BEIESP). This is an open access article under the CC BY-NC-ND license (http://creativecommons.org/licenses/by-nc-nd/4.0/) patch antennas have very small operating bandwidth. There have been several attempts to deal with this problem to a certain degree such as the use of a dielectric high-permit substrates [3], the use of defective ground structures (DGS) [4], or combining several substrates [5], addition of air gaps and shorting of pins [6], use of metamaterials [7], addition of

slots on patches [8], use of modified patches are used instead of conventional shapes [9], use of various optimization algorithms e.g. PSO [10] and creating complex patch structures using GA [11], or using slot dipole CPW-fed antenna design [12]. High impedance bandwidth (S11 < 10 $\mathrm{dB}$ ), flat gain response over the radiating bandwidth are the major challenges for an efficient wideband antenna. In all weather conditions, including fog, sandstorm and other difficult condition, X-band has exceptionally high connectivity. X-band supports voice, information, images and HD video communication.In this paper, a modified CPW-fed slot dipole is optimized to achieve high gain, bandwidth and minimum return losses.

This paper is made up of four sections. Section II presents the steps followed in GA optimization, antenna design and fabrication. Section III discussed the performance of slot-dipole antenna using the simulated and measured results. Section IV, finally, summarizes the paper.

\section{OPTIMIZATION, DESIGN AND FABRICATION OF CPW-FED SLOT DIPOLE ANTENNA}

The antenna proposed is in X-band of super high frequency to radiate at a resonating frequency of $10.5 \mathrm{GHz}$. The main design objective was to achieve minimum values of S11 at resonating frequency, to have a minimum bandwidth of 500 $\mathrm{MHz}$ and to achieve minimum gain of $5 \mathrm{~dB}$ at resonating frequency. A simple Genetic Algorithm (GA) based optimization is utilized to achieve the design objectives.MATLAB is integrated with HFSS environment to implement GA algorithm code. Figure 1 is the flow-chart representation of Genetic Algorithm (GA) optimizer [11] Table 1 addresses selection of Genetic Algorithm parameters for optimization e.g. population type and size, number of generations, selection criteria, etc. Figure 3 displays the corresponding converged antenna using GA. Proposed design is simulated and characterized on FR4 substrate, as it is inexpensive and easier in fabrication. The FR4 substrate has a height of $1.6 \mathrm{~mm}$, a dielectric constant of 4.3 and a tangent loss of 0.02 . 
Design and Optimization of Genetic Algorithm (GA) based High Gain and Directive CPW-Fed Slot Dipole Antenna for Wideband Applications

Table 2 describes the overall dimension of the antenna as well as all simulated and calculated performance. Equations (1-5) shows the cost function utilized for the purpose of optimization and Figure 2 demonstrates the convergence rate for the Genetic Algorithm (GA) based optimization technique.

$$
\begin{aligned}
& \text { Cost }=\left[-(3 * \text { Gain })-(20 * B W)+S_{11(\text { Res })}\right] \\
& \text { Gain }=\left\{\begin{array}{c}
10 \mathrm{~dB} ; \quad \text { for Gain }_{\text {Cal }} \geq 10 \mathrm{~dB} \\
\text { Gain }_{\text {Cal }} ; \quad \text { for Gain }_{\text {Cal }}<10 \mathrm{~dB}
\end{array}\right\} \\
& B W=\left\{\begin{array}{cl}
1.5 \mathrm{GHz} ; & \text { for } B W_{\text {Cal }} \geq 1.5 \mathrm{Ghz} \\
B W_{\text {Cal }} ; & \text { for } B W_{\text {Cal }}<1.5 \mathrm{Ghz}
\end{array}\right\} \\
& B W_{\text {Cal }}=f_{H}-f_{L} \\
& S_{11(\text { Res })}=\left\{\begin{array}{cl}
-30 d B ; & \text { for } S_{11} \leq-30 d B \\
S_{11} ; & \text { for } S_{11}>-30 d B
\end{array}\right\}
\end{aligned}
$$

Eq 4.

Eq 5.

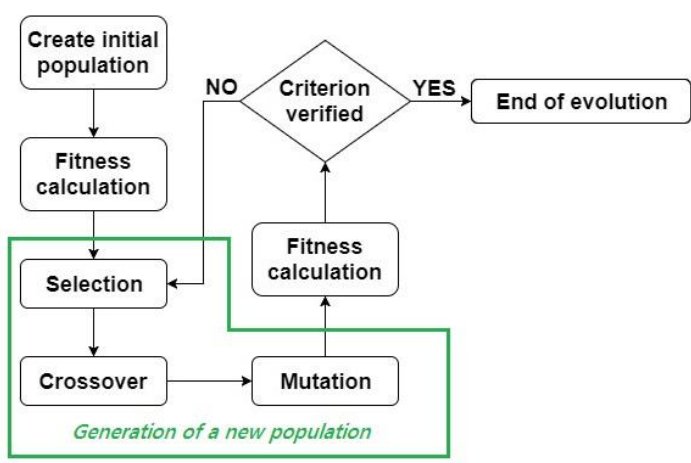

Fig. 1: Flow chart representation of Genetic Algorithm (GA) optimizer [11].

Table 1: Selection of Genetic Algorithm parameters for optimization

\begin{tabular}{|c|c|}
\hline Parameters & Selected Values \\
\hline Population Type & Bit String \\
\hline $\begin{array}{c}\text { No. of decision variables } \\
\text { (in Bit) }\end{array}$ & 34 \\
\hline $\begin{array}{c}\text { Total number of } \\
\text { Generations and } \\
\text { Population Size }\end{array}$ & 200 \\
\hline Scaling Basis & Rank \\
\hline Selection Criteria & Roulette \\
\hline Reproduction Elite Count & 2 \\
\hline Mutation & Uniform (0.01) \\
\hline Crossover and its fraction & $\begin{array}{c}\text { Single Point } \\
\text { Crossover (0.8) }\end{array}$ \\
\hline $\begin{array}{c}\text { Penalty factor and Initial } \\
\text { Penalty }\end{array}$ & 100 and 10 \\
\hline
\end{tabular}

Table 2: Parameters of Converged Antenna

\begin{tabular}{|c|c|}
\hline Antenna Parameters & Values \\
\hline $\begin{array}{c}\text { Resonating Frequency } \\
\text { (Band of Operation) }\end{array}$ & $10.5 \mathrm{GHz}$ (X-Band) \\
\hline Reflection Coefficient $\left(\mathrm{S}_{11}\right)$ & $\begin{array}{c}-25.83 \mathrm{~dB} \text { (Sim) and } \\
-23.08 \text { (Meas.) }\end{array}$ \\
\hline Bandwidth & $\begin{array}{c}1.4 \mathrm{GHz} \text { (Sim) and } \\
1.3 \mathrm{GHz} \text { (Meas.) }\end{array}$ \\
\hline $\begin{array}{c}\text { Gain at Resonating } \\
\text { Frequency }\end{array}$ & $5.61 \mathrm{~dB}$ (Sim) \\
\hline $\begin{array}{c}\text { Directivity at Resonating } \\
\text { Frequency }\end{array}$ & $11.87 \mathrm{~dB}$ (Sim) \\
\hline
\end{tabular}

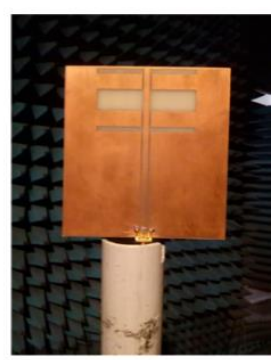

Fig. 3: (A) Proposed antenna with dimensions (B) Manufactured antenna

\section{RESULTS AND DISCUSSION}

The proposed antenna shows $-25.83 \mathrm{~dB}$ (simulated values) and -23.08 (measured values) of S11 at the resonant frequency of $10.5 \mathrm{GHz}$. The proposed antenna shows 1.4 $\mathrm{GHz}$ (simulated values) and $1.3 \mathrm{GHz}$ (measured values) of bandwidth.

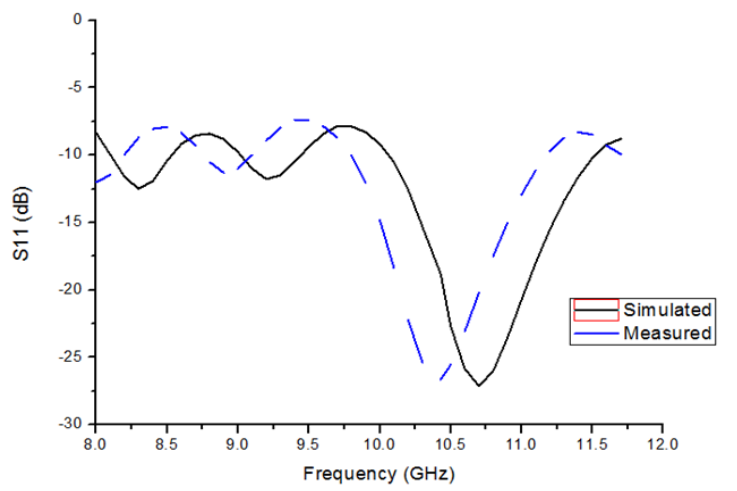

Fig. 4: Plot of measured vs. simulated return losses (S11) of the converged antenna design. 
Figures 5 and 6 show two and three dimensional (2D and $3 \mathrm{D})$ radiation patterns. The $2 \mathrm{D}$ plots in Figure 5 shows the E-Plane, H-plane, Co and Cross polarization plots at 10.5 $\mathrm{GHz}$ resonant frequency.

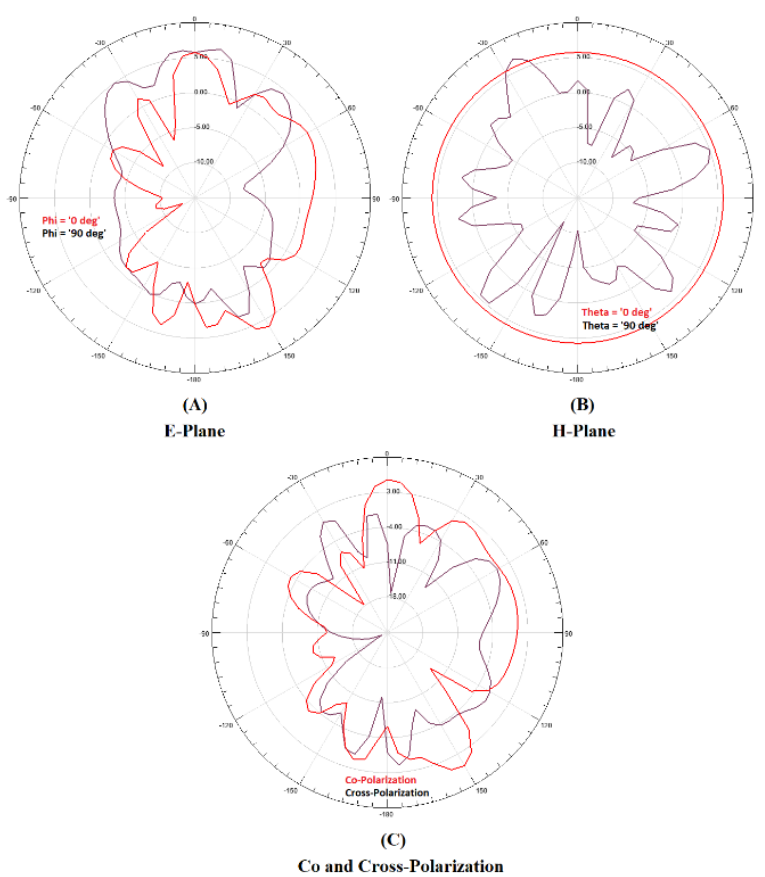

Fig. 5: Simulated Radiation Patterns at resonant frequency of 10.5 GHz - (A) E-Plane, (B) H-Plane, (C) Co and Cross-polarization
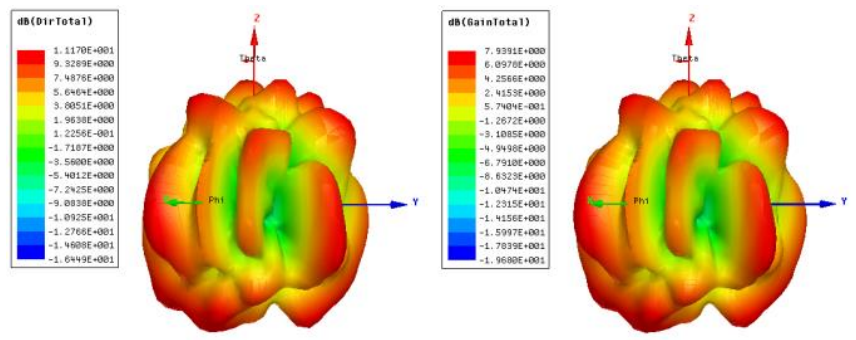

Fig. 6: Simulated values of 3D Radiation Pattern at resonant frequency of $10.5 \mathrm{GHz}$

A plot of gain and directivity with respect to the bandwidth of the antenna is presented in Figure 7. At the resonant frequency of $10.5 \mathrm{GHz}$, proposed antenna exhibits higher values of simulated gain and directivity (5.61 dB and 11.87 $\mathrm{dB}$ respectively).

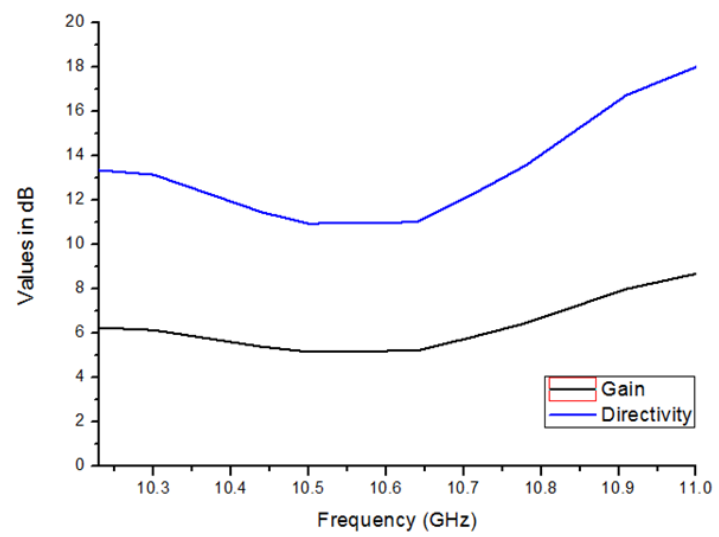

Fig. 7: Simulated values of directivity vs. gain of the converged antenna design

\section{CONCLUSION}

The discussion in this paper incorporates genetic algorithm to optimize the design of a high gain X-band CPW-fed slot-dipole antenna. The antenna is built on an inexpensive and easy to produce FR4 substratum. The proposed antenna design has a wide operating bandwidth of $1.4 \mathrm{GHz}$ (simulated) and $1.3 \mathrm{GHz}$ (measured) over the X-band, a return loss (S11) of $-25.83 \mathrm{~dB}$ (simulated) and -23.08 (measured) and a resonating frequency gain and directivity of $5.61 \mathrm{~dB}$ (simulated) and $11.87 \mathrm{~dB}$ (simulated) at $10.5 \mathrm{GHz}$. The simulations and the results measured are in good agreement.

\section{ACKNOWLEDGMENT}

This research work is supported by UPES Dehradun, Uttarakhand, India.

\section{REFERENCES}

1. Ranjan Mishra, "An Overview of Microstrip Antenna", HCTL Open International Journal of Technology Innovations and Research (IJTIR), Volume 21, Issue 2, August 2016.

2. Balanis, C.A., “Antenna Theory: Analysis and Design”, John Wiley, 2005.

3. Lo, T. K. and Y. Hwang, "Microstrip antennas of very high permittivity for personal communications", Asia Pacific Microwave Conference, Vol. 1, 253-256, 1997.

4. Elftouh, H., N. A. Touhami, M. Aghoutane, S. ElAmrani, A. Tazon, and M. Boussouis, "Miniaturized microstrip patch antenna with defected ground structure", Progress In Electromagnetics Research C, Vol. 55, 25-33, 2014.

5. Ali Y.E.M., and A.J.A. Qader, "Design of Dual Band Circular Polarization Stacked Microstrip Antenna for GPS Applications", Al-Rafidain Engineering Journal 22.3:225-232, 2014.

6. Jayasinghe J.M.J.W. and D.N. Uduwawala, "A Novel Multiband Miniature Planar Inverted F Antenna Design for Bluetooth and WLAN Applications", International Journal of Antennas and Propagation, 2015.

7. Jahromi A.G., F. Mohajeri and N. Feiz, "Miniaturization of a Rect-angular Microstrip Patch Antenna Loaded with Metamaterial", World Academy of Science, Engineering and Technology, 7: 668-671, 2013.

8. Islam M.T., and M. Samsuzzaman, "Miniaturized Dual Band Multi slotted Patch Antenna on Polytetrafluoroethylene Glass Microfiber Reinforced for C/X Band Applications", The Scientific World Journal, 2014

9. Jayasinghe J.M.J.W. and D.N. Uduwawala, "Optimization of the performance of patch antennas using genetic algorithms", Journal of National Science Foundation 41. 2: 115-122, 2013.

10. Robinson, J., Rahmat-Samii, Y., "Particle Swarm Optimization in Electromagnetics", IEEE Transactions on Antennas and Propagation 52 2, 397-407, 2004

11. M. Lamsalli, A. El Hamichi, M. Boussouis, N. Amar Touhami, and T. Elhamadi, "Genetic algorithm optimization for microstrip patch antenna miniaturization”, Progress In Electromagnetics Research Letters, Vol 60, 113-120, 2016.

12. J. Li, J. Guo, H. Shi, B. He, and A. Zhang, "CPW-Fed Stub-Loaded Slot Dipole Antenna Design for Dual-Band Operation," Progress In Electromagnetics Research Letters, Vol. 60, 67-72, 2016

\section{AUTHORS PROFILE}

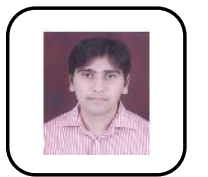

Prof. Raj Gaurav Mishra, is currently working as an Assistant Professor (Selection Grade) in the Department of Electrical and Electronics Engineering at the School of Engineering, University of Petroleum and Energy Studies, Dehradun, Uttarakhand (India). He is having around 12+ years of experience in academics and research. Prof. Mishra has received his M.S. in Space Engineering from the Department of Space Studies, Umea University, Kiruna, Sweden in the year 2007. He is currently pursuing his Ph.D.

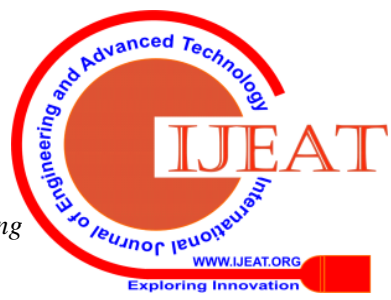


thesis in Microstrip Antenna Design at University of Petroleum and Energy Studies, Dehradun. Mr. Mishra is an author of 36 international refereed journal, international conference papers and book chapters, 1 Indian patent and 3 edited books.

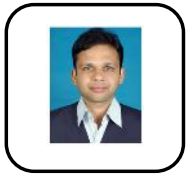

Dr. Ranjan Mishra, is currently working as an Associate Professor in the Department of Electrical and Electronics Engineering, School of Engineering at University of Petroleum and Energy Studies, Dehradun, Uttarakhand (India). He has around 19+ years of experience in academics and research. Dr. Mishra has received his Ph.D. in Microstrip Antenna Design from University of Petroleum and Energy Studies, Dehradun in the year 2016. Dr. Mishra is an author of 24 international refereed journal and international conference papers and 4 edited books.

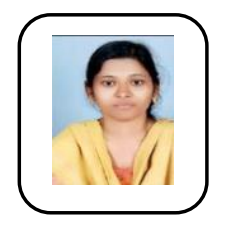

Dr. N. Prasanthi Kumari, has received herPh D in Electronics and Communication Engineering from UPES Dehradun. She is currently working as an Associate Professor in the Department of Electrical and Electronics Engineering, School of Engineering at University of Petroleum and Energy Studies, Dehradun, Uttarakhand (India).

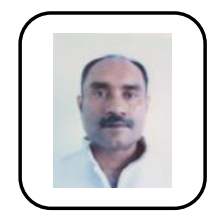

Dr. Sushabhan Choudhury, has received hisPh D in Electronics Engineering from UPES Dehradun.He is currently working as a Professor and Head in the Department of Electrical and Electronics Engineering, School of Engineering at University of Petroleum and Energy Studies, Dehradun, Uttarakhand (India).

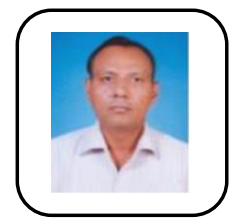

Dr. Piyush Kuchhal, has received his M.Sc and Ph D in Physics from IIT Roorkee. He is currently working in UPES as Professor in Physics. He has published 50 scopus indexed papers journal and 12 patent. He has a vast teaching and research experience of $20+$ years in the area of Microwave, Engineering electromagnetism and Photovoltaic Solar cell. He also published 30 papers in International conference and presided over many committees. 